\title{
Cost-effectiveness of self-monitoring of blood glucose in patients with type 2 diabetes mellitus managed without insulin
}

\author{
Chris Cameron MSc, Doug Coyle MSc PhD, Ehud Ur MD, Scott Klarenbach MD MSc
}

Previously published at www.cmaj.ca

$\infty \quad$ See related research article by Gomes and colleagues, page 35

\section{ABSTRACT}

Background: The benefits of self-monitoring blood glucose levels are unclear in patients with type 2 diabetes mellitus who do not use insulin, but there are considerable costs. We sought to determine the cost effectiveness of self-monitoring for patients with type 2 diabetes not using insulin.

Methods: We performed an incremental cost-effectiveness analysis of the self-monitoring of blood glucose in adults with type 2 diabetes not taking insulin. We used the United Kingdom Prospective Diabetes Study (UKPDS) model to forecast diabetes-related complications, corresponding qualityadjusted life years and costs. Clinical data were obtained from a systematic review comparing self-monitoring with no self-monitoring. Costs and utility decrements were derived from published sources. We performed sensitivity analyses to examine the robustness of the results.

Results: Based on a clinically modest reduction in hemoglobin $A_{1 c}$ of $0.25 \%$ (95\% confidence interval $0.15-0.36$ ) estimated from the systematic review, the UKPDS model predicted that self-monitoring performed 7 or more times per week reduced the lifetime incidence of diabetes-related complications compared with no self-monitoring, albeit at a higher cost (incremental cost per quality-adjusted life year $\$ 113643)$. The results were largely unchanged in the sensitivity analysis, although the incremental cost per qualityadjusted life year fell within widely cited cost-effectiveness thresholds when testing frequency or the price per test strip was substantially reduced from the current levels.

Interpretation: For most patients with type 2 diabetes not using insulin, use of blood glucose test strips for frequent self-monitoring ( $\geq 7$ times per week) is unlikely to represent efficient use of finite health care resources, although periodic testing (e.g., 1 or 2 times per week) may be costeffective. Reduced test strip price would likely also improve cost-effectiveness.

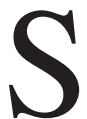

elf-monitoring of blood glucose in patients with diabetes who use insulin may contribute to improved glycemic control and reduced hypoglycemia by allowing for self-adjustments in insulin dose to be made based on meter readings. ${ }^{1}$ Self-monitoring may also allow for appropriate changes in diet and physical activity to be made. However, the benefits of self-monitoring of blood glucose for patients not using insulin are less clear. Hypoglycemia is less frequent in this population ${ }^{2}$ and is confined mainly to those taking secretagogues. The degree to which patients can adjust the dose of oral antidiabetes drugs in response to readings is limited.

Nevertheless, self-monitoring of blood glucose is routinely recommended for patients who are not using insulin. ${ }^{1}$ This results in major investments in this technology by patients and payers. ${ }^{3}$ In 2006, \$250 million was spent on blood glucose test strips in 8 publicly funded drugs plans in Newfoundland and Labrador, Nova Scotia, Quebec, Ontario, Manitoba, Saskatchewan and British Columbia, while over \$120 million was spent in privately funded drug plans in Canada. ${ }^{4}$ In some publicly funded drug plans in Canada, blood glucose test strips are among the top 5 classes in terms of total expenditure, ${ }^{5}$ with costs exceeding those for all oral antidiabetes drugs combined. ${ }^{4,6}$ It is estimated that more than $50 \%$ of the total expenditure on blood glucose test strips is for patients with type 2 diabetes who are not using insulin. ${ }^{3}$ Costs related to test strips are expected to rise steadily ${ }^{5,7}$ because of the increasing prevalence of type 2 diabetes. ${ }^{8}$

Decisions about the prescribing and reimbursement of blood glucose test strips require consideration of information about the costs and clinical benefits. ${ }^{9,10}$ As part of a larger initiative to determine the optimal use of this technology, we sought to determine the cost-effectiveness of self-monitoring of blood glucose for patients with type 2 diabetes who do not use insulin, based on data from our systematic review ${ }^{11}$ of the available clinical evidence.

From the Canadian Optimal Medication Prescribing and Utilization Service (Cameron), Canadian Agency for Drugs and Technologies in Health, Ottawa, Ont., the Department of Epidemiology and Community Medicine (Coyle), University of Ottawa, Ottawa, Ont., the Division of Endocrinology (Ur), St. Paul's Hospital and Vancouver General Hospital, University of British Columbia, Vancouver, BC; the Department of Medicine (Klarenbach), University of Alberta, Calgary, Alta; and the Canadian Optimal Medication Prescribing and Utilization Service Expert Review Committee (Ur, Klarenbach).

CMAJ 2009. DOI:10.1503/cmaj.090765 


\section{Methods}

\section{Model and data sources}

We performed an incremental cost-utility analysis of selfmonitoring of blood glucose using the United Kingdom Prospective Diabetes Study (UKPDS) Outcomes Model. This computer simulation model forecasts long-term health outcomes and cost consequences in patients with type 2 diabetes (Appendix 1, available at www.cmaj.ca/cgi/content/full/ cmaj.090765/DC1 ${ }^{12}$ ) The model estimates the risks of 7 diabetes-related complications based on data obtained from 3642 patients with type 2 diabetes who were enrolled in UKPDS. Projections from this model have been validated using published clinical and epidemiological studies. ${ }^{13}$

Relevant clinical outcomes associated with selfmonitoring of blood glucose in adults with type 2 diabetes not using insulin were derived from our systematic review ${ }^{11}$ of randomized controlled trials and observational studies comparing self-monitoring with no self-monitoring. We assessed a number of outcomes, including hemoglobin $\mathrm{A}_{1 \mathrm{C}}\left(\mathrm{HbA}_{1 \mathrm{C}}\right)$, hypoglycemia, quality of life, long-term complications of diabetes and mortality. The methodology and results of the review have been reported in full. ${ }^{11}$

The UKPDS model simulates the occurrence of clinical events over the expected remaining lifetime of a patient with type 2 diabetes (maximum 40 years). Simulated patients were characteristic of those enrolled in randomized controlled trials included in the systematic review. ${ }^{11}$ The ages and baseline risk factors for diabetes-related complications of the simulated patients (e.g., baseline $\mathrm{HbA}_{1 \mathrm{c}}$ level, systolic blood pressure, cholesterol level) have been reported. ${ }^{14}$ Data on the history of 7 major diabetes-related complications captured in the UKPDS Outcomes Model (Appendix 1) were not reported in the randomized controlled trials included in the systematic review. Therefore, we assumed that patients in the hypothetical cohort in the base-case analysis did not have a history of these complications. We made this assumption because most randomized controlled trials excluded patients with impending diabetes-related complications or a history of serious disease, and because less than $1 \%$ of patients in Canada with type 2 diabetes aged 45-65 years have a history of stroke, blindness, amputation or renal disease. ${ }^{14-16}$

We performed this analysis from the perspective of a Canadian ministry of health. ${ }^{17}$ We obtained the unit costs for blood glucose test strips ( $\$ 0.73 /$ strip) and dispensing fees $(\$ 7.00$ per 100 strips) from the Ontario Public Drug Program..$^{18,19} \mathrm{We}$ did not incorporate the costs for glucometers and lancets, because they are often made available to patients at no charge by manufacturers ${ }^{20}$ and they are usually not covered by public drug plans. We assumed an average daily consumption of 1.29 blood are $\$ 8505$. ${ }^{21}$ glucose test strips per patient on the basis of the weighted average of actual (where reported) or per-protocol testing frequencies across randomized controlled trials included in the systematic review. This estimate closely coincided with the results of a recent utilization study of Ontario Public Drug Program beneficiaries. ${ }^{3}$

Resource utilization and costs (Table 1) associated with managing diabetes-related complications were obtained from the Ontario Ministry of Health and Long-term Care. ${ }^{23}$ Inpatient, outpatient and emergency department visits, prescription drug claims, long-term care and home care costs for managing diabetes-related complications were included in the model. ${ }^{23}$ The costs were inflated to 2008 Canadian dollars using the Health Component of the Canadian Consumer Price Index..$^{26}$

Both costs and quality-adjusted life-years were discounted at a rate of $5 \%$, as recommended by the guidelines of the Canadian Agency for Drugs and Technologies in Health. ${ }^{17}$

\section{Outcomes}

The primary outcome measure in the current analysis was quality-adjusted life-years, which capture both quantity and quality of life. We obtained quality weights for included health states from a US catalogue of EuroQol 5-dimension (EQ-5D) scores. ${ }^{21,22}$ Patients with noninsulin-treated type 2 diabetes without a history of diabetes-related complications were assumed to have an EQ-5D score of $0.753 .^{21,22}$ Disutilities associated with diabetes-related complications are reported in Table $1 .^{21-24}$

\section{Statistical analysis}

We performed 1-, 2- and multi-way sensitivity analyses to examine the robustness of the results to changes in the parameters and model assumptions. A number of randomized controlled trials included in the systematic review included patients who were taking either oral antidiabetes agents or made lifestyle interventions. We therefore assessed the effect

Table 1: Modelled management costs and utility decrements

\begin{tabular}{|c|c|c|c|c|}
\hline \multirow[b]{3}{*}{ Condition } & \multicolumn{2}{|c|}{ Annual cost, ${ }^{* 1}$ Can $\$, 2008 \dagger$} & \multicolumn{2}{|c|}{ Utility decrement $\ddagger^{22,23}$} \\
\hline & \multicolumn{2}{|c|}{ Year } & \multicolumn{2}{|c|}{ Year } \\
\hline & 1 & $\geq 2$ & 1 & $\geq 2$ \\
\hline Myocardial infarction§ & 17324 & 2695 & -0.041 & -0.012 \\
\hline Ischemic artery disease & 5394 & 3114 & -0.041 & -0.024 \\
\hline Heart failure & 15766 & 4420 & -0.055 & -0.018 \\
\hline Stroke§ & 23475 & 3257 & -0.052 & -0.040 \\
\hline Amputation & 36416 & 4987 & -0.280 ** & -0.280 ** \\
\hline Blindness & 2884 & 2055 & -0.050 & -0.050 \\
\hline End-stage renal disease & 23365 & 10604 & $-0.263 * *$ & $-0.263 * *$ \\
\hline
\end{tabular}

*The average annual cost for patients without diabetes-related complications who are not selfmonitoring their blood glucose levels was $\$ 1507,{ }^{21}$ while those who self-monitored had an annual cost of $\$ 1507^{20}$ plus the cost of the blood glucose test strips.

tInflated to 2008 Canadian dollars using the health component of the Consumer Price Index.

$\ddagger$ A utility is a quantitative expression of an individual's preference for a health state; 1 represents a state of perfect health and 0 represents a state equivalent to death. ${ }^{25}$

§Management costs for a fatal myocardial infarction are \$9039; management costs for a fatal stroke

$* *$ Utility decrements were not available from the US catalogue ${ }^{.22,23}$ therefore, they were obtained from another source that utilized the EQ-5D instrument. ${ }^{19}$ 
of $\mathrm{HbA}_{1 \mathrm{C}}$ inputs derived from pooling across the subset of randomized controlled trials in which all patients received oral antidiabetic agents or those in which all patients received nonpharmacological interventions. We tested the effect of varying the cost of the test strips, testing frequency, baseline $\mathrm{HbA}_{\mathrm{lC}}$ levels and patient characteristics. We also tested including a utility decrement for symptomatic hypoglycemia. The detailed results from additional sensitivity analyses are reported elsewhere. ${ }^{27}$ We generated cost-effectiveness acceptability curves for the reference case, as well as for alternative testing frequencies and test strip prices, to illustrate the probability that the self-monitoring of blood glucose is cost-effective across a range of decision-makers' willingness-to-pay thresholds. ${ }^{28}$

\section{Results}

Our systematic review ${ }^{11}$ identified 7 randomized controlled trials, ${ }^{29-35}$ enrolling a total of 2270 patients with type 2 diabetes managed with oral antidiabetes agents or lifestyle measures

Table 2: Cumulative incidence of diabetes-related complications over a 40-year period among patients with type 2 diabetes who do not use insulin who selfmonitor their blood glucose levels and those who do not self-monitor

\begin{tabular}{|c|c|c|c|c|}
\hline \multirow[b]{2}{*}{ Condition } & \multicolumn{2}{|c|}{ Cumulative incidence, \% } & \multirow[b]{2}{*}{$\begin{array}{l}\text { Absolute risk } \\
\text { reduction, \% }\end{array}$} & \multirow[b]{2}{*}{$\begin{array}{c}\text { Number } \\
\text { needed to treat }\end{array}$} \\
\hline & $\begin{array}{l}\text { No self- } \\
\text { monitoring }\end{array}$ & $\begin{array}{c}\text { Self- } \\
\text { monitoring }\end{array}$ & & \\
\hline $\begin{array}{l}\text { Myocardial } \\
\text { infarction }\end{array}$ & 36.58 & 36.21 & 0.38 & 266 \\
\hline $\begin{array}{l}\text { Ischemic artery } \\
\text { disease }\end{array}$ & 13.12 & 13.04 & 0.09 & 1136 \\
\hline Heart failure & 17.64 & 17.20 & 0.44 & 228 \\
\hline Stroke & 16.34 & 16.14 & 0.20 & 500 \\
\hline Amputation & 3.55 & 3.34 & 0.21 & 467 \\
\hline Blindness & 8.69 & 8.49 & 0.19 & 518 \\
\hline $\begin{array}{l}\text { End-stage renal } \\
\text { disease }\end{array}$ & 2.29 & 2.21 & 0.08 & 1299 \\
\hline
\end{tabular}

Table 3: Benefits, costs and incremental cost utility ratios for self-monitoring blood glucose levels among patients with type 2 diabetes not using insulin*

\begin{tabular}{|c|c|c|c|}
\hline Measure† & $\begin{array}{l}\text { No self- } \\
\text { monitoring }\end{array}$ & Self-monitoring & Difference \\
\hline Life years gained & 9.87038 & 9.89812 & 0.028 \\
\hline $\begin{array}{l}\text { Quality-adjusted life years } \\
\text { gained }\end{array}$ & 7.29806 & 7.32191 & 0.024 \\
\hline Total direct costs, Can\$ & 27997 & 30708 & 2711 \\
\hline $\begin{array}{l}\text { Incremental cost per life-year } \\
\text { gained }\end{array}$ & & & 97 729‡ \\
\hline $\begin{array}{l}\text { Incremental cost per quality- } \\
\text { adjusted life-year gained }\end{array}$ & & & $113643 \S$ \\
\hline
\end{tabular}

alone. These trials compared self-monitoring of blood glucose with no self-monitoring. The pooled difference in $\mathrm{HbA}_{1 \mathrm{c}}$ was statistically significant in favour of self-monitoring (weighted mean difference $-0.25 \%, 95 \%$ confidence intervals $[\mathrm{CI}]-0.36 \%$ to $-0.15 \%$ ). The results were similar in a number of subgroup analyses, including the intensity of education about the interpretation and application of the test results, testing frequency, diabetes duration and baseline $\mathrm{HbA}_{1 \mathrm{C}}$ level. Based on limited evidence, self-monitoring has failed to show consistent benefits in terms of quality of life, patient satisfaction, hypoglycemia, longterm complications of diabetes and mortality. These outcomes were therefore not included in the cost-effectiveness analysis of the reference case.

The $\mathrm{HbA}_{1 \mathrm{C}}$ benefit of self-monitoring from the systematic review, ${ }^{11}$ when analyzed using the UKPDS Outcomes Model, translated into small differences (ranging from $0.08 \%$ to $0.40 \%$, depending on the outcome) in cumulative incidence rates of diabetes-related complications (Table 2). The numbers of patients who would need to perform self-monitoring to avert 1 diabetes-related complication over a 40-year period ranged from 228 to 1299 (Table 2). Self-monitoring of blood glucose was associated with an additional 0.024 quality-adjusted life-years and increased lifetime costs of $\$ 2711$, resulting in an incremental cost-utility ratio of $\$ 113643$ per quality-adjusted life-year gained (Table 3). Cost-effectiveness acceptability curves (Figure 1 and Figure 2) revealed a probability of less than $10 \%$ that self-monitoring would be costeffective at a willingness-to-pay threshold of $\$ 50000$ per quality-adjusted lifeyear, and a $40 \%$ probability of costeffectiveness at a threshold of \$100 000 per quality-adjusted life-year. ${ }^{10}$

The reduction in $\mathrm{HbA}_{1 \mathrm{C}}$ associated with self-monitoring in the only randomized trial that reported results for patients not using pharmacotherapy for diabetes ${ }^{30}$ was smaller than in the overall analysis (weighted mean difference $-0.05 \%, 95 \%$ CI -0.23 to 0.33 ), resulting in a cost per qualityadjusted life- year gained of \$292 144 . The cost per quality-adjusted life- year based on the pooled $\mathrm{HbA}_{1 \mathrm{C}}$ difference in the subset of randomized controlled trials $^{30,31,35}$ in which all patients used oral antidiabetes agents was \$91 724 per quality-adjusted life-year gained. The results were highly sensitive to the price of the test strips and, to a lesser extent, testing frequency (Table 4; Figure 1 and Figure 2), 1,2,7, 14-16,23,29-42 but the results were largely unchanged if we varied most other parameters and assumptions. 


\section{Interpretation}

Our cost-effectiveness analysis was based on a systematic review of the available clinical evidence, ${ }^{11}$ which showed a clinically modest ${ }^{43}$ benefit in $\mathrm{HbA}_{\mathrm{IC}}$ levels among patients with type 2 diabetes who self-monitored their blood glucose levels. This result translated into a small reduction in diabetes-related complications in the economic model. We found that self- monitoring at a frequency of about 9 tests per week was associated with an incremental cost of $\$ 113643$ per qualityadjusted life-year gained, relative to no self-monitoring. Thus, the clinical benefits of self-monitoring and the associated costsavings do not offset the cost of the blood glucose test strips.

In our sensitivity analyses, we explored conditions under which cost-effectiveness estimates may vary. The results did not change substantially with changes in the assumed $\mathrm{HbA}_{1 \mathrm{C}}$ benefit

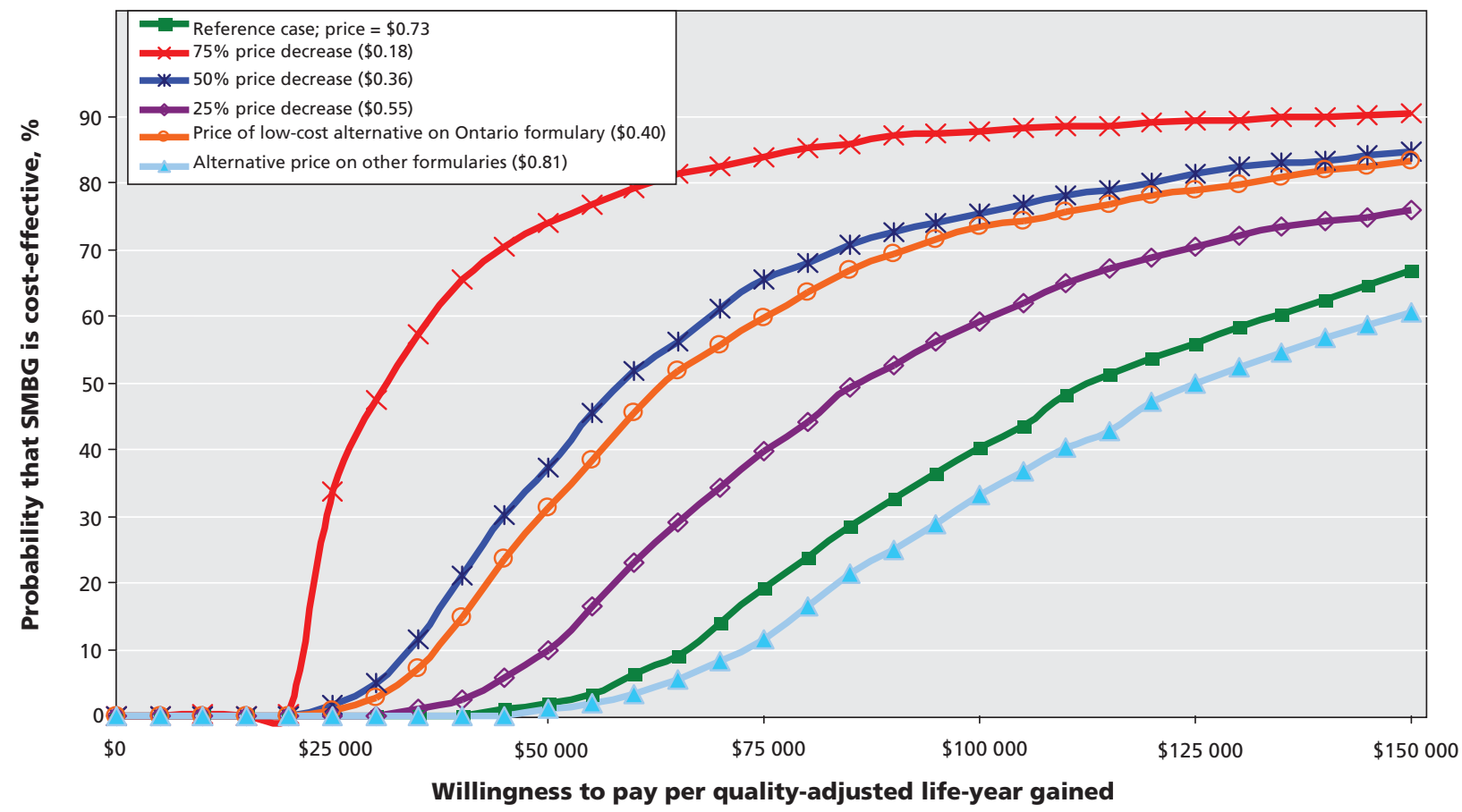

Figure 1: Cost-effectiveness acceptability curves for different prices per blood glucose test strip. These curves show the probability that performing self-monitoring of blood glucose (SMBG) is cost-effective relative to not performing self-monitoring in patients with type 2 diabetes who are not using insulin, across a range of decision-makers' willingness to pay-thresholds.

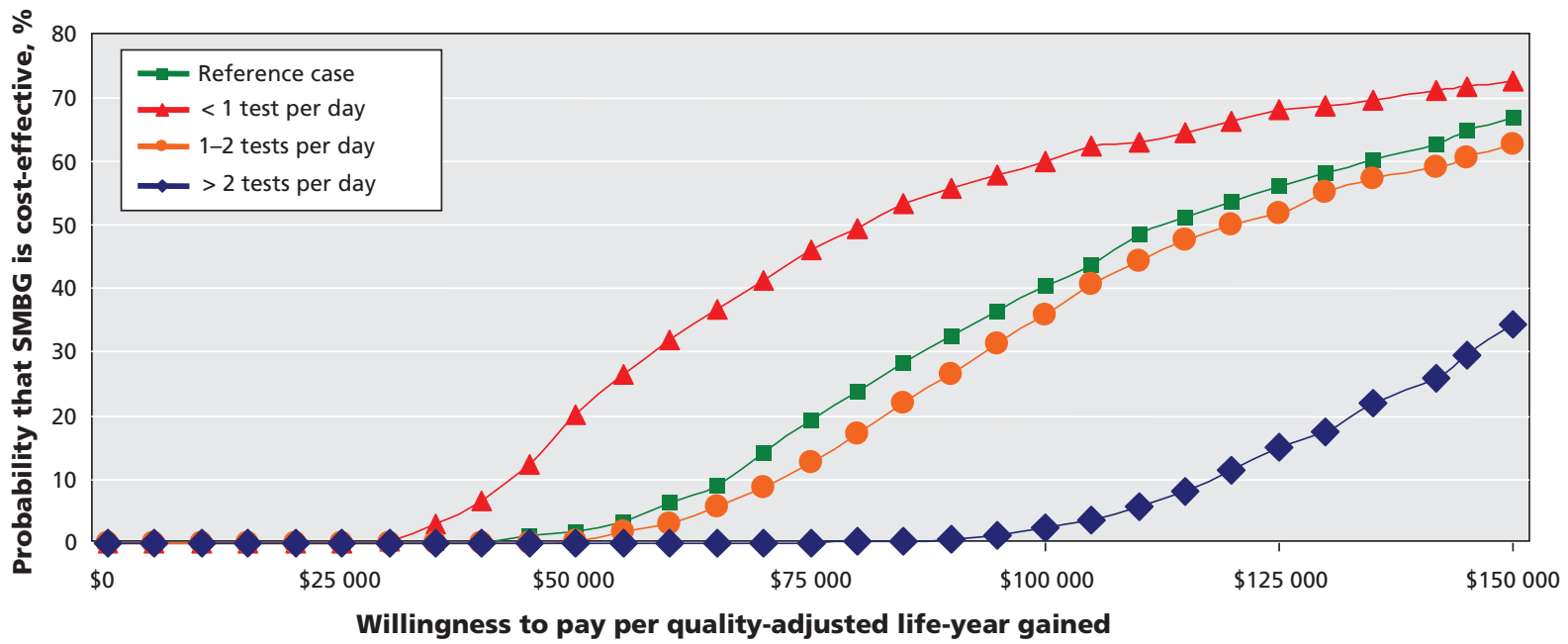

Figure 2: Cost-effectiveness acceptability curves for 2-way sensitivity analyses, in which $\mathrm{HbA}_{1 \mathrm{c}}$ estimates of effect and self-monitoring of blood glucose (SMBG) testing frequencies were both varied. 
of self-monitoring, higher baseline $\mathrm{HbA}_{\mathrm{c}}$ levels, or when the cohort was modified to reflect patient characteristics (e.g., diabetes-related complications, duration of diabetes) observed in the Canadian setting (Table 4). Cost-effectiveness estimates, however, were highly sensitive to changes in the price per test strip and testing frequency. Cost-effectiveness acceptability

Table 4: Incremental cost-utility ratios for the comparison of self-monitoring of blood glucose with no self-monitoring in patients with type 2 diabetes not using insulin

\begin{tabular}{|c|c|}
\hline Analysis & ICUR (Can\$/QALY) \\
\hline Reference case & 113643 \\
\hline \multicolumn{2}{|l|}{ One-way sensitivity analyses } \\
\hline Lower limit of $95 \% \mathrm{Cl}$ for WMD in $\mathrm{HbA}_{1 \mathrm{c}}$ from $7 \mathrm{RCTs} s^{25-31}\left(\Delta \mathrm{HbA}_{1 \mathrm{c}}=-0.39 \%\right)$ & 77706 \\
\hline Upper limit of $95 \% \mathrm{Cl}$ for WMD in $\mathrm{HbA}_{1 \mathrm{c}}$ from $7 \mathrm{RCTs}^{25-31}\left(\Delta \mathrm{HbA}_{1 \mathrm{c}}=-0.15 \%\right)$ & 189376 \\
\hline WMD in $\mathrm{HbA}_{1 c}$ from good-quality $\mathrm{RCTs}^{25,29,31}\left(\Delta \mathrm{HbA}_{1 \mathrm{c}}=-0.21 \%{ }^{33}\right)$ & 133829 \\
\hline$\Delta \mathrm{HbA}_{1 c}$ estimate from observational study ${ }^{33}\left(\Delta \mathrm{HbA}_{1 \mathrm{c}}=-0.57 \%^{33}\right)$ & 47512 \\
\hline WMD in $\mathrm{HbA}_{1 \mathrm{c}}$ from RCTs ${ }^{26,30}$ that used intensive education* $\left(\Delta \mathrm{HbA}_{1 \mathrm{c}}=-0.28 \%^{33}\right)$ & 99916 \\
\hline Price per test strip reduced by $25 \%$ (Can $\$ 0.55 /$ strip) & 86129 \\
\hline Price per test strip reduced by $50 \%$ (Can $\$ 0.36 /$ strip) & 58615 \\
\hline Price per test strip reduced by $75 \%$ (Can $\$ 0.18 /$ strip) & 31101 \\
\hline Lowest price per test strip in Ontario Drug Benefits Program (Can\$0.40/strip) & 63892 \\
\hline Alternative formulary list price (Can\$0.81/strip) & 123143 \\
\hline $\begin{array}{l}\text { History of diabetes-related complications reflective of patients in the DICE study and Canadian diabetes } \\
\text { atlases }{ }^{13-15,32, \pm}\end{array}$ & 89656 \\
\hline \multicolumn{2}{|l|}{ No. of tests per weekt } \\
\hline $1(0.14 / \text { day })^{34}$ & 6322 \\
\hline $2(0.29 / \text { day })^{34}$ & 19571 \\
\hline $4(0.57 / \text { day })^{34}$ & 46445 \\
\hline $7(1 / \text { day })^{35}$ & 86168 \\
\hline $12(1.71 / \text { day })^{25,30}$ & 152095 \\
\hline \multicolumn{2}{|l|}{ Two-way sensitivity analyses } \\
\hline Self-monitoring $<1 /$ day, $\left(\Delta \mathrm{HbA}_{1 \mathrm{c}}=-0.20 \% \text {; frequency }=0.77 / \text { day }\right)^{25-27}$ & 81654 \\
\hline Self-monitoring 1-2/day, $\left(\Delta \mathrm{HbA}_{1 \mathrm{c}}=-0.26 \% \text {; frequency }=1.46 / \text { day }\right)^{29,31}$ & 122416 \\
\hline Self-monitoring $>2 /$ day, $\left(\Delta \mathrm{HbA}_{1 \mathrm{c}}=-0.47 \% \text {; frequency }=3.5 / \text { day }\right)^{28,30}$ & 169120 \\
\hline Baseline $\mathrm{HbA}_{1 \mathrm{c}}<8.0 \%\left(\mathrm{WMD}\right.$ in $\mathrm{HbA}_{1 \mathrm{c}} \%=0.16 \%$, baseline $\left.\mathrm{HbA}_{1 \mathrm{c}}=7.5 \%\right)$ & 213503 \\
\hline Baseline $\mathrm{HbA}_{1 c^{\prime}} 8.0 \%-10.5 \%\left(\mathrm{WMD}\right.$ in $\mathrm{HbA}_{1 \mathrm{c}} \%=0.30 \%$, baseline $\left.\mathrm{HbA}_{1 \mathrm{c}}=8.7 \%\right)$ & 94443 \\
\hline \multicolumn{2}{|l|}{ Multi-way sensitivity analyses } \\
\hline Patients using OADs, 3 RCTs $s^{26,27,31} \S$ & 91724 \\
\hline Patients using insulin, ${ }^{34} * * 1 \mathrm{RCT}^{26,27,31}$ & 91693 \\
\hline Patients using diet-only therapy, $+\dagger 1 \mathrm{RCT}^{13}$ & 292144 \\
\hline
\end{tabular}

Note: $\mathrm{Cl}=$ confidence interval, DICE = Diabetes in Canada Evaluation, $\mathrm{HbA}_{1 \mathrm{c}}$ hemoglobin $\mathrm{A} 1 \mathrm{c}, \Delta \mathrm{HbA}_{1 \mathrm{c}}=$ changes in $\mathrm{HbA} \mathrm{Ac}_{\mathrm{c}}$ levels, ICUR $=$ incremental cost-utility ratio, $\mathrm{OAD}=$ oral antidiabetes drug, $\mathrm{OALY}=$ quality-adjusted life-year, $\mathrm{RCT}=$ randomized controlled trial, $\mathrm{WMD}=\mathrm{Weighted}$ mean difference. *Instruction in self-interpretation and application.

tOne-way sensitivity analysis in which the $\mathrm{HbA}_{1 c}$ estimate of effect was held constant at $-0.25 \%(95 \% \mathrm{Cl}-0.36 \%$ to $-0.15 \%)$ favouring self-monitoring and testing frequency is varied.

¥Proportion of patients with a history of complications reflective of patients in the Diabetes in Canada Evaluation and Ontario and Alberta Diabetes Atlases (i.e. $1 \%$ of patients were assumed to have history of blindness, ${ }^{13-15}$ end-stage renal disease, ${ }^{13-15}$ amputation; ${ }^{13-15,32} 4 \%{ }^{36,37}$ and $2 \%{ }^{32}$ of patients had history of atrial fibrillation and peripheral vascular disease on diagnosis of diabetes; $2 \%$ have history of stroke; $9 \%$ have history of myocardial infarction; ${ }^{13-15} 4 \%$ have congestive heart failure; ${ }^{13-15}$ and $10 \%$ had a history of ischemic heart disease ${ }^{13-15}$; average time since event was based on data from the Ontario Diabetes Economic Mode ${ }^{16}$ ). $\S B$ aseline $\mathrm{HbA}_{1 \mathrm{c}}=8.3 \%$; WMD in $\mathrm{HbA}_{1 \mathrm{c}} \%$ : $-0.24(-0.36,-0.11)$; mean age $=61 \mathrm{yr}$; mean duration of diabetes $=4.9 \mathrm{yr}$; frequency $=1.08$ test strips/day; cost of test strip $=$ Can $\$ 0.73 /$ strip; time horizon $=40 \mathrm{yr}$; discount rate $=5 \%$; we assumed no history of diabetes-related complications, because these data were not reported in 3 RCTs. ${ }^{1,2}$

**Based on data from Barnett and colleagues, ${ }^{26,27,31}$ we assumed that $7 \%$ of patients would experience a symptomatic hypogylcemic episode with an excess of 2.38 episodes per year in the no self-monitoring arm. For each episode, we assumed that patients move to a health state characterized by moderate anxiety, with or without depression and have some problems with performing usual activities. ${ }^{38}$ Consequently, a disutility of $0.167^{38}$ was used for 15 min for each episode; baseline $\mathrm{HbA}_{1 \mathrm{c}}=8.3 \%$; WMD in $\mathrm{HbA}_{1 \mathrm{c}} \%$ : $-0.24(-0.36,-0.11)$; mean age $=61 \mathrm{yr}$; mean duration of diabetes $=4.9 \mathrm{yr}$; frequency $=1.08$ test strips/day; cost of test strip $=$ Can $\$ 0.73 /$ strip; time horizon $=40 \mathrm{yr}$; discount rate $=5 \%$; we assumed no history of diabetes-related complications, because these data were not reported in 3 RCTs in which patients used oral antidiabetes drugs. ${ }^{26,27}$

t†Baseline $\mathrm{HbA}_{1 \mathrm{c}}=7.5 \%$; WMD in $\mathrm{HbA}_{1 \mathrm{c}} \%:-0.05(-0.33,0.23)$; mean age $=66 \mathrm{yr}$; mean duration of diabetes = $3 \mathrm{yr}$; frequency $=0.71$ test strips/day; cost of test strip $=$ Can $\$ 0.73 /$ strip; time horizon $=40 \mathrm{yr}$; discount rate $=5 \%$; we assumed no history of diabetes-related complications, because these data were not reported in 3 RCTs. ${ }^{1,2,6}$ 
curves showed that a greater than $50 \%$ reduction in the price per test strip would result in a substantial increase in the probability that self-testing is cost-effective. Results from 1- and 2-way sensitivity analyses also suggested that lower testing frequencies (e.g., 1-2 tests per week) would be the most likely to yield favourable cost-effectiveness estimates. This is not surprising because the incremental $\mathrm{HbA}_{1 \mathrm{C}}$ benefit of each subsequent test per day is likely to be progressively smaller, while the cost of test strips increases linearly with the number used. Further welldesigned randomized controlled trials are needed to assess the role of self-monitoring at lower testing frequencies in patients with type 2 diabetes who are not using insulin.

Our results differ from those reported in earlier incremental cost-utility analyses..$^{36,44,45}$ Two of the previous studies ${ }^{36,44}$ found more favourable cost-effectiveness estimates, likely because of the use of data from an observational study, ${ }^{37}$ which found larger $\mathrm{HbA}_{\mathrm{IC}}$ differences in favour of self-monitoring than our systematic review. Conversely, the other economic study ${ }^{45}$ reported results less favourable to self-monitoring primarily because the $\mathrm{HbA}_{1 \mathrm{C}}$ results were from a single clinical trial. Differences in utility decrements may also explain some of the differences in the results between these studies. Health-related quality-of-life scores in 2 earlier analyses ${ }^{36,44}$ were based on data from patients with type 2 diabetes $^{24}$ and the authors did not control for nondiabetes-related complications and other confounding variables such as income, education, ethnicity and number of comorbidities, all of which affect health-related quality of life. In contrast, we obtained utility decrements from a community-based EQ-5D catalogue in the United States, ${ }^{21,22}$ which was adjusted for determinants of health (e.g., age, sex, income, education) and chronic conditions other than diabetes.

The choice of economic model may also contribute to differences between our analysis and previous studies. We used the UKPDS Outcomes Model, ${ }^{12}$ while 2 previous studies ${ }^{36,44}$ used the Center for Outcomes Research (CORE) Diabetes Model. ${ }^{46}$ The UKPDS Outcomes Model uses updated regression equations derived from UKPDS68, ${ }^{12}$ while the CORE Diabetes Model ${ }^{46}$ uses regression equations derived from the older UKPDS56 Risk Engine. ${ }^{47}$ Thus, the UKPDS Outcomes Model ${ }^{12}$ provides a more accurate estimate of events examined in UKPDS because it uses a wider variety of inputs, including knowledge of previous events, and incorporates updated risk factor data over time. ${ }^{36}$

\section{Limitations}

Our study had several limitations. First, cost-effectiveness results are limited by available clinical evidence. ${ }^{11}$ Second, the model used $\mathrm{HbA}_{1 \mathrm{C}}$, a surrogate outcome, to project the occurrence of long-term consequences related to diabetes. The validity of this outcome continues to be debated in the literature, particularly for cardiovascular outcomes in patients with type 2 diabetes. ${ }^{48,49}$ Thus, the benefits of self-monitoring blood glucose in terms of reduced rates of complications may be overstated. Third, the UKPDS model ${ }^{36}$ does not explicitly incorporate a number of morbidities (e.g., peripheral neuropathy, ulceration) related to diabetes. As well, some complications are represented as a single outcome (e.g., blindness, endstage renal disease) in the model rather than intermediate states such as (e.g., retinopathy, nephropathy) that may them- selves be associated with reduced health-related quality of life. Since a reduced incidence of these outcomes because of selfmonitoring and the resulting benefits in terms of health-related quality of life and reduced treatment costs may not be captured, the use of the UKPDS model may result in a slight overestimation of the incremental cost-effectiveness ratios. ${ }^{12}$ Longterm follow-up data from UKPDS may provide additional data for these states, at which time a reassessment of the costeffectiveness of self-monitoring in patients with type 2 diabetes may be warranted.

Finally, the analysis of the reference case did not incorporate hypoglycemic episodes, including severe hypoglycemia. Episodes of hypoglycemia, however, are infrequent ${ }^{2}$ in patients with type 2 diabetes not using insulin, with the exception of those using insulin secretagogues (i.e., sulfonyureas, meglinatides). Additionally, there is little evidence that use of self-monitoring alters the risk of hypoglycemia, even in patients using sulfonylureas. ${ }^{35}$ If future studies reveal that selfmonitoring of blood glucose is associated with a reduced risk of hypoglycemia, especially severe hypoglycemia, this analysis should be revisited given the potential impact of this complication on clinical outcomes and resource utilization.

\section{Conclusion}

We found that self-monitoring of blood glucose was associated with a modest reduction in $\mathrm{HbA}_{1 \mathrm{C}}$ in patients with type 2 diabetes not treated with insulin. Within the limitations of modelling and the available clinical data, frequent use of self-monitoring in this population is associated with unfavourable cost-effectiveness estimates and is unlikely to represent an efficient use of finite health care resources. This result did not change substantially with changes to a number of inputs, including the type of antidiabetes therapy, degree of glycemic control at baseline and history of diabetes-related complications. However, reduced frequency (e.g., 1 or 2 times per week) or a reduction in the price of test strips would likely improve the costeffectiveness of routine self-monitoring in this population.

\section{This article has been peer reviewed.}

Competing interests: Scott Klarenbach and Ehud Ur have received honoraria for participation in the COMPUS Expert Review Committee. None declared for Chris Cameron and Doug Coyle.

Contributors: All of the authors contributed to the conception and design of the study. Chris Cameron conducted the analysis, and all authors assisted in the interpretation of the results. Chris Cameron, with the help of Scott Klarenbach, Doug Coyle and Ehud Ur, drafted the manuscript. All of the authors critically reviewed the manuscript for important intellectual content and approved the final version submitted for publication.

Acknowledgements: The authors thank Melissa Severn for developing and implementing the literature search strategies, Heather Bennett for her input into study design and Sumeet Singh and Denis Belanger for their critical review of the manuscript. Scott Klarenbach is supported by Population Health Investigator Award from Alberta Heritage Foundation for Medical Research.

Funding: This cost-effectiveness was conducted by researchers at the Canadian Agency for Drugs and Technologies in Health (CADTH). CADTH is an independent, not-for-profit agency funded by Canadian federal, provincial and territorial governments to provide credible, impartial advice and evidencebased information about the effectiveness of drugs and other health technologies to Canadian health care decision-makers. For more information, visit www.cadth.ca. 


\section{REFERENCES}

1. Canadian Diabetes Association 2008 clinical practice guidelines for the prevention and management of diabetes in Canada. Can J Diabetes 2008;32(Suppl 1):i-S201. Available: www.diabetes.ca/files/cpg2008/cpg-2008.pdf (accessed 2009 Oct. 7).

2. Bodmer M, Meier C, Krahenbuhl S, et al. Metformin, sulfonylureas, or other antidiabetes drugs and the risk of lactic acidosis or hypoglycemia: a nested casecontrol analysis. Diabetes Care 2008;31:2086-91.

3. Canadian Agency for Drugs and Technologies in Health. Optimal therapy report: current utilization of blood glucose test strips in Canada. Ottawa (ON): The Agency; 2009. Available: www.cadth.ca/media/pdf/compus_CU_Report-BGTS.pdf (accessed 2009 Oct. 7).

4. Cameron C, Virani A, Dean H, et al. Current utilization and expenditure on blood glucose test strips in Canada. Can J Diabetes. In press.

5. 2005/06 report card for the Ontario drug benefit program [PowerPoint presentation] Toronto (ON): Ministry of Health and Long-Term Care; 2006. Available: www.health.gov.on.ca/english/public/pub/ministry_reports/odb_report05/drug_rep. html (accessed 2009 Oct. 7).

6. Utilization of oral antiglycemics in Canada. [unpublished dataset]. Ottawa (ON): Brogan, Inc.; 2008.

7. 2004/05 report card for the Ontario drug benefit program. [Powerpoint presentation]. Toronto (ON): Ministry of Health and Long-Term Care; 2005. Available: www.health.gov.on.ca/english/public/pub/ministry_reports/odb_report04/drug_rep .html (accessed 2009 Oct. 7).

8. Diabetes in Canada. Highlights from the National Diabetes Surveillance System 2004-2005. Ottawa (ON): Public Health Agency of Canada; 2008. Available: www.phac-aspc.gc.ca/publicat/2008/dicndss-dacsnsd-04-05/pdf/dicndss-04-05eng.pdf (accessed 2009 Oct. 7).

9. Laupacis A. Economic evaluations in the canadian common drug review. Pharmacoeconomics 2006;24:1157-62.

10. Laupacis A, Feeny D, Detsky AS, et al. How attractive does a new technology have to be to warrant adoption and utilization? Tentative guidelines for using clinical and economic evaluations. CMAJ 1992;146:473-81.

11. Canadian Agency for Drugs and Technologies in Health. Systematic review of use of blood glucose test strips for the management of diabetes mellitus. Ottawa (ON): The Agency; 2008. Available: www.cadth.ca/media/pdf/BGTS_SR_Report_of _Clinical_Outcomes.pdf (accessed 2009 Oct 9).

12. Clarke PM, Gray AM, Briggs A, et al. A model to estimate the lifetime health outcomes of patients with type 2 diabetes: the United Kingdom Prospective Diabetes Study (UKPDS) Outcomes Model (UKPDS no. 68). Diabetologia 2004;47:1747-59.

13. Mount Hood 4 Modeling Group. Computer modeling of diabetes and its complications: a report on the fourth Mount Hood Challenge Meeting. Diabetes Care 2007;30: 1638-46 Available http://care.diabetesjournals.org/cgi/reprint/30/6/1638 (accessed 2009 Oct. 7).

14. Alberta diabetes atlas 2007. Edmonton (AB): Institute of Health Economics; 2007. Available: www.achord.ca/documents/AlbertaDiabetesAtlas2007_002.pdf (accessed 2009 Oct. 7).

15. Hux JE, Booth GL, Slaughter PM, et al., editors. Diabetes in Ontario: an ICES practice atlas. Toronto $(\mathrm{ON})$ : Institute for Clinical Evaluative Sciences; 2003. Available: www.ices.on.ca/webpage.cfm?site_id=1\&org_id=31\&morg_id=0\& gsec_id=0\&item_id=1312 (accessed 2009 Oct. 7).

16. Harris SB, Ekoe JM, Zdanowicz Y, et al. Glycemic control and morbidity in the Canadian primary care setting (results of the diabetes in Canada evaluation study). Diabetes Res Clin Pract 2005;70:90-7.

17. Canadian Agency for Drugs and Technologies in Health. Guidelines for the economic evaluation of health technologies: Canada. 3rd ed. Ottawa (ON): The Agency; 2006. Available: www.cadth.ca/media/pdf/186_EconomicGuidelines_e.pdf (accessed 2009 Oct. 7)

18. Ontario drug benefit formulary/comparative drug index: electronic version. [database online]. Toronto (ON): Ministry of Health and Long-Term Care; 2008. Available: www.health.gov.on.ca/english/providers/program/drugs/odbf_eformulary.html (accessed 2007 Feb. 13).

19. Ontario drug benefit: dispensing fees. Toronto (ON): Ministry of Health and LongTerm Care; 2007. Available: www.health.gov.on.ca/english/public/pub/drugs /dispense.html (accessed 2008 June 23).

20. OneTouch blood glucose meters. Burnaby (BC): LifeScan Canada Ltd; 2007. Available: www.onetouch.ca/english/index.asp (accessed 2009 Oct. 7).

21. O'Reilly D, Hopkins R, Blackhouse G, et al. Development of an Ontario Diabetes Economic Model (ODEM) and application to a multidisciplinary primary care diabetes management program. Hamilton (ON): Program for Assessment of Technology in Health (PATH); 2006. Available: www.path-hta.ca/diabetes.pdf (accessed 2009 Oct. 7)

22. Sullivan PW, Ghushchyan V. Preference-based EQ-5D index scores for chronic conditions in the United States. Med Decis Making 2006;26:410-20.

23. Sullivan PW, Lawrence WF, Ghushchyan V. A national catalog of preference-based scores for chronic conditions in the United States. Med Care 2005;43:736-49.

24. Clarke P, Gray A, Holman R. Estimating utility values for health states of type 2 diabetic patients using the EQ-5D (UKPDS 62). Med Decis Making 2002;22:340-9.

25. Berger ML, Bingefors K, Hedblom EC, et al., editors. Health care cost, quality, and outcomes: ISPOR book of terms. Lawrenceville (NJ): International Society for Pharmacoeconomics and Outcomes Research; 2003.
26. Consumer price index (CPI), 2001 basket content, monthly (1992=100). In: $C A N$ SIM table. Ottawa (ON): Statistics Canada; 2007.

27. Canadian Agency for Drugs and Technologies in Health. Cost-effectiveness of blood glucose test strips in the management of adult patients with diabetes [DRAFT]. Ottawa (ON): The Agency; 2009. Available: www.cadth.ca/media/pdf /compus_Draft_BGTS_Consolidated_Econ_Report.pdf (accessed 2009 Oct. 7).

28. Dahlof C, Dimenas E, Olofsson B. Documentation of an instrument for assessment of subjective CNS-related symptoms during cardiovascular pharmacotherapy. Cardiovasc Drugs Ther 1989;3:919-27.

29. Davidson MB, Castellanos M, Kain D, et al. The effect of self monitoring of blood glucose concentrations on glycated hemoglobin levels in diabetic patients not taking insulin: a blinded, randomized trial. Am J Med 2005;118:422-5.

30. Farmer A, Wade A, Goyder E, et al. Impact of self monitoring of blood glucose in the management of patients with non-insulin treated diabetes: open parallel group randomised trial. $B M J$ 2007;335:132.

31. Guerci B, Drouin P, Grangé V, et al. Self-monitoring of blood glucose significantly improves metabolic control in patients with type 2 diabetes mellitus: the AutoSurveillance Intervention Active (ASIA) study. Diabetes Metab 2003;29:587-94.

32. Muchmore DB, Springer J, Miller M. Self-monitoring of blood glucose in overweight type 2 diabetic patients. Acta Diabetol 1994;31:215-9.

33. O'Kane MJ, Bunting B, Copeland M, et al. Efficacy of self monitoring of blood glucose in patients with newly diagnosed type 2 diabetes (ESMON study): randomised controlled trial. BMJ 2008:336:1174-7.

34. Schwedes U, Siebolds M, Mertes G; SMBG Study Group. Meal-related structured self-monitoring of blood glucose: effect on diabetes control in non-insulin-treated type 2 diabetic patients. Diabetes Care 2002;25:1928-32. Available: http://care.diabetes journals.org/cgi/reprint/25/11/1928 (accessed 2009 Oct. 7).

35. Barnett AH, Krentz AJ, Strojek K, et al. The efficacy of self-monitoring of blood glucose in the management of patients with type 2 diabetes treated with a gliclazide modified release-based regimen. A multicentre, randomized, parallel-group, 6-month evaluation (DINAMIC 1 study). Diabetes Obes Metab 2008;10:1239-47.

36. Palmer AJ, Dinneen S, Gavin JR, et al. Cost-utility analysis in a UK setting of selfmonitoring of blood glucose in patients with type 2 diabetes. Curr Med Res Opin 2006; 22:861-72

37. Karter AJ, Ackerson LM, Darbinian JA, et al. Self-monitoring of blood glucose levels and glycemic control: the Northern California Kaiser Permanente Diabetes Registry. Am J Med 2001;111:1-9.

38. Scherbaum WA, Ohmann C, Abholz HH, et al. Effect of the frequency of selfmonitoring blood glucose in patients with type 2 diabetes treated with oral antidiabetic drugs-a multi-centre, randomized controlled trial. PLoS One 2008:3:e3087.

39. Canadian Diabetes Association 2003 clinical practice guidelines for the prevention and management of diabetes in Canada. Can J Diabetes 2003;27(Suppl 2):i-S140. Available: www.diabetes.ca/cpg2003/downloads/cpgcomplete.pdf (accessed 2009 Oct. 7).

40. Ostgren CJ, Merlo J, Rastam L, et al. Atrial fibrillation and its association with type 2 diabetes and hypertension in a Swedish community. Diabetes Obes Metab 2004;6:367-74.

41. Go AS, Hylek EM, Phillips KA, et al. Prevalence of diagnosed atrial fibrillation in adults: national implications for rhythm management and stroke prevention: the AnTicoagulation and Risk Factors in Atrial Fibrillation (ATRIA) Study. JAMA 2001;285:2370-5.

42. Calculating the U.S. population-based EO-5D index score. Rockville (MD): Agency for Healthcare Research and Quality; 2005. Available: www.ahrq.gov/rice /EQ5Dscore.htm (accessed 2009 Oct. 7).

43. Bowker SL, Majumdar SR, Johnson JA. Systematic review of indicators and measurements used in controlled studies of quality improvement for type-2 diabetes. Can J Diabetes 2005;29:230-8. Available: www.diabetes.ca/files/Johnson_Systematic_Review-pages\%20230-238.pdf (accessed 2009 Oct. 7).

44. Tunis SL, Minshall ME. Self-monitoring of blood glucose in type 2 diabetes: costeffectiveness in the United States. Am J Manag Care 2008;14:131-40.

45. Simon J, Gray A, Clarke P, et al. Cost effectiveness of self monitoring of blood glucose in patients with non-insulin treated type 2 diabetes: economic evaluation of data from the DiGEM trial. BMJ 2008;336:1177-80.

46. Palmer AJ, Roze S, Valentine WJ, et al. The CORE Diabetes Model: projecting long-term clinical outcomes, costs and cost-effectiveness of interventions in diabetes mellitus (types 1 and 2) to support clinical and reimbursement decision-making. Curr Med Res Opin 2004;20(Suppl 1):S5-26.

47. Stevens RJ, Kothari V, Adler AI, et al.; United Kingdom Prospective Diabetes Study (UKPDS) Group. The UKPDS risk engine: a model for the risk of coronary heart disease in type II diabetes (UKPDS 56). Clin Sci (Lond) 2001;101:671-9.

48. Lassere MN, Johnson KR, Boers M, et al. Definitions and validation criteria for biomarkers and surrogate endpoints: development and testing of a quantitative hierarchical levels of evidence schema. J Rheumatol 2007;34:607-15.

49. Rosen CJ. The rosiglitazone story-lessons from an FDA Advisory Committee meeting. N Engl J Med 2007;357:844-6.

Correspondence to: $M r$. Chris Cameron, Health Economist, Canadian Optimal Medication Prescribing and Utilization Service (COMPUS), Canadian Agency for Drugs and Technologies in Health (CADTH), 600-865 Carling Ave., Ottawa ON K1S 5S8; chrisc@cadth.ca 